\title{
1,3-Diphenylpropan-1-ones as Allosteric Modulators of $\alpha 7$ nACh Receptors with Analgesic and Antioxidant Properties
}

\author{
Manuel Criado, ${ }^{\text {,a }}$ Beatriz Balsera, ${ }^{b}$ José Mulet, ${ }^{\text {a }}$ Salvador Sala, ${ }^{\text {a }}$ Francisco Sala, ${ }^{a}$ \\ Roberto de la Torre-Martínez, ${ }^{c}$ Asia Fernández-Carvajal, ${ }^{c}$ Antonio Ferrer-Montiel, ${ }^{c}$ \\ Silvia Moreno-Fernández, ${ }^{d}$ Marta Miguel, ${ }^{d}$ María Jesús Pérez de Vega ${ }^{b}$ and Rosario \\ González-Muñiz*,b \\ anstituto de Neurociencias, Universidad Miguel Hernández-CSIC, 03050 Sant Joan \\ d'Alacant, Spain \\ ${ }^{b}$ Instituto de Química Médica, IQM-CSIC, Juan de la Cierva 3, 28006 Madrid, Spain \\ 'Instituto de Biología Molecular y Celular, Universidad Miguel Hernández, Avenida de la \\ Universidad s/n, 03202 Elche (Alicante), Spain \\ 'Instituto de Investigación en Ciencias de la Alimentación (CSIC-UAM, CEI+UAM), C/ \\ Nicolás Cabrera 9, 28049 Madrid, Spain
}

\author{
Authors for correspondence \\ Dr. Rosario González-Muñiz \\ Instituto de Química Médica, IQM-CSIC, Juan de la Cierva, 3 \\ 28006 Madrid, Spain \\ Tel.: 34915680063 \\ Fax: 34915644853 \\ Email: rosario.gonzalezmuniz@iqm.csic.es \\ Prof. Manuel Criado \\ Instituto de Neurociencias, Universidad Miguel Hernández-CSIC, \\ 03050 Sant Joan d'Alacant, Spain \\ Tel.: \\ Fax: \\ Email: manuel.criado@umh.es
}

Background: Nicotine acethylcholine receptors (nAChRs) play critical roles in cognitive processes, neuroprotection, and inflammation. Results: According to their substituents, 1,3-diphenylpropan-1-one derivatives act as $\alpha 7$ nAChRs negative allosteric modulators (OMe) or Type I positive allosteric modulators (PAMs, OH). Compounds 7 and 31 were the most effective (989 and 666\% enhancement of AChinduced currents) and potent ( $\mathrm{EC}_{50}: 12.9$ and $\left.6.85 \mu \mathrm{M}\right)$ PAMs. They exhibited strong radical scavenging values. Compound 31, selective over other neuronal nAChR subtypes and with acceptable pharmacokinetic profile, showed antinociceptive effects in a model of inflammatory pain. Conclusions: Compound $\mathbf{3 1}$ is a novel, potent and selective $\alpha 7$ nAChR PAM, displaying antioxidant and analgesic activities. The 1,3diphenylpropan-1-one scaffold could be the base toward more advanced PAMs for the treatment of nAChR-mediated diseases. 
Key Words:

Alpha7 nAChR

Positive allosteric modulator

Antioxidant

Inflammation

Pain 
Nicotinic acetylcholine receptors (nAChRs) are ligand-gated channels widely expressed in the nervous system, and involved in a variety of disorders, including psychiatric, neurodegenerative and antiinflammatory processes[1-3]. Among them, the neuronal $\alpha 7$ receptor subtype ( $\alpha 7$ nAChRs) has attracted considerable interest as a potential target for therapeutic intervention in schizophrenia, Alzheimer's disease and different pain conditions $[4,5]$. Most of the compounds described as modulators of these channels are competitive agonists or antagonists that interact at the orthosteric binding site of the endogenous ligand, acetylcholine [2, 6]. However, recent efforts have been focused on exploring the pharmacological diversity of compounds able to interact with the receptor at allosteric binding sites $[7,8]$. These can be allosteric agonists, positive allosteric modulators (PAMs), which potentiate the agonist-evoked responses without activating or desensitizing the receptor in a direct way, negative allosteric modulators (NAMs), able to reduce the effects of the orthosteric ligand, and silent allosteric modulators (SAMs) that bind to the allosteric site without producing a change in orthosteric binding or efficacy [9]. There are two types of PAMs, differing in their effects on receptor desensitization. Type I PAMs have little or no effect on the rate of agonist-induced desensitization, while Type II cause a noteworthy duration of channel opening, due to delayed desensitization [7].

The search for allosteric modulators of $\alpha 7 \mathrm{nAChRs}$ is of great interest because they could selectively regulate this subtype versus other nicotinic receptors, and even homologue serotonine receptors $\left(5-\mathrm{HT}_{3}\right)$, thus avoiding many of the secondary effects associated to ligands that target the highly conserved acetylcholine binding site [8]. Despite the limited number of compounds described as $\alpha 7$ nAChR PAMs, several of them have advanced towards clinical development [10-23]. Within the families of $\alpha 7$ nAChR allosteric modulators, a series of cyclopentatetrahydroquinoline-8-sulfonamide derivatives is worth mentioning, since they showed different pharmacological properties depending on the nature, number and position of certain substituents [9, 24]. For instance, minor chemical changes like the configuration, the interchange of halogens, or different patterns of methyl substitution in the aromatic moiety at position 2 of the tetrahydroisoquinoline ring resulted in either PAMs (Type I or II), NAMs, SAMs, or allosteric agonists [9, 24].

Upon screening of a heterogenous collection of small natural products, we identified a polyhydroxy substituted chalcone, Isoliquiritigenin (1, Figure $\mathbf{1})$, as a selective Type I PAM of $\alpha 7 \mathrm{nAChRs}$ [25]. The screening of a collection of one hundred commercial chalcones led to the identification of its regioisomer $\mathbf{2}$, as a potent and selective $\alpha 7$ nAChR Type II PAM. This compound was taken as a hit for the preparation of a series of polysubstituted chalcone analogues, aimed at improving its pharmacodynamic profile. Modifications on the number, position or nature of the substituents, led to several analogues with interesting properties as $\alpha 7$ nAChRs PAMs. One of the new prepared analogues, compound 3, exhibited much higher potency than the model parent compound $\mathbf{2}$, and a similar increase in the peak of ACh-evoked currents mediated by human $\alpha 7$ nAChRs expressed in Xenopus oocytes [25]. In addition, compound $\mathbf{3}$ displayed neuroprotective activities in vitro, and antinociceptive effects in a mechanical hyperalgesia in vivo test. Although this compound showed low toxicity, the conjugated double bond can be seen as a drug structural alert, because of 
its high chemical reactivity towards oxidation and potential capacity as Michael acceptor versus nucleophiles. Therefore, analogues of $\mathbf{3}$ lacking the $\alpha, \beta$-unsaturated carbonyl linker could serve to mitigate the risk of potential idiosyncratic drug toxicity [26].

To this aim, and to further investigate the potentiality of this series of $\alpha 7$ nAChRs PAMs, in this contribution we explore the reduction of the double bond or the carbonyl group that form the linker chain joining the two aromatic rings in this family of chalcones. The transformation of the double bond into a pyrrole ring was also performed. While the methoxy-substituted 1,3-diphenylpropa-1-one derivatives behave as $\alpha 7$ nAChRs NAMs, the hydroxyl analogues showed, in general, a typical Type I PAM profile. One of these derivatives, the reduced analogue of chalcone $\mathbf{2}$ was shown to significantly inhibit thermal hyperalgesia in vivo while the corresponding to chalcone 3 did not, a different behavior that can be explained in terms of their dissimilar pharmacokinetic properties. In addition, the hydroxy 1,3-diphenylpropa-1-ones, as well as chalcone $\mathbf{3}$, show remarkable antioxidant properties.

\section{Results \& discussion}

\section{Chemistry}

First, we were interested in the reduction of the double bond of the spacer chain, keeping intact the carbonyl group. Starting from methoxy chalcone 4, attempts to hydrogenate it over $\mathrm{Pd} / \mathrm{C}$ were not completely satisfactory, since the main reaction product was the alcohol 5, that result from the concomitant hydrogenation of the double bond and the carbonyl group, while the desired product 6 was the minor component of the reaction. Preparation of 6 was finally achieved in good yield by performing the $\mathrm{Pd} / \mathrm{C}$ hydrogenation in the presence of diphenyl sulfide, a catalyst poison that selectively hydrogenates olefin and acetylene functionalities without hydrogenolysis of aromatic carbonyls [27]. Polyhydroxylated compound 7 was obtained from the methoxy propan-1-one analogue 6 by treatment with $\mathrm{BBr}_{3}$ in $\mathrm{Cl}_{2} \mathrm{CH}_{2}$ [28], the same procedure followed in the preparation of the hydroxychalcone series (Figure 2). However, a similar treatment failed in the case of compound $\mathbf{5}$ that decomposed under these reaction conditions.

The good $\alpha 7 \mathrm{nAChR}$ potentiation value found for compound 7 , as we will comment later, prompted us to prepare the propan-1-one analogues of the rest of our previously described hydroxylated chalcones [25]. Thus, hydrogenation of the double bond of methoxylated chalcones 8-12 using the $\mathrm{Pd}-\mathrm{C} / \mathrm{Ph}_{2} \mathrm{~S}$ system led to propan-1ones 13-17 in good to excellent yield. Deprotection of the methoxy groups of 13-15 afforded the expected hydroxy derivatives 18-20, while the treatment of compounds 16 and 17 with $\mathrm{BBr}_{3}$ in $\mathrm{DCM}$ gave untreatable complex mixtures (Figure 3).

Alternatively, compounds 24-26, monohydroxylated in ring $A$, were obtained by direct hydrogenation of the corresponding hydroxyl-chalcones 21-23, previously prepared by us (Figure 4) [25].

For the synthesis of derivatives monosubstituted in ring $B$, we first prepared monohydroxy dimethoxychalcones $\mathbf{2 7}$ and 28, by condensation of commercial 2,5dimethoxyacetophenone and the corresponding 2-hydroxy and 4hydroxybenzaldehydes. The procedure involved then hydrogenation to propan-1-ones 29 and 30, and subsequent deprotection of the methoxy groups. Compound 31, the reduced analogue of chalcone $\mathbf{2}$, was obtained in this way, but deprotection of MeO- 
groups of 29 did not work, recovering the starting material unaltered, probably because of steric hindrance around the 2'-OMe group. (Figure 5).

On the other hand, attempts to selectively reduce the carbonyl group, keeping the double bond unaltered, were unsuccessful. Several assays using $\mathrm{BH}_{4} \mathrm{Na}$, alone or in the presence of $\mathrm{CeCl}_{3}$, following the methodology described by Luche, [29] led to complex mixtures, difficult to handle, due to partial reduction of the double bond and formation of unidentified minoritary byproducts that difficulted the purification and lowered the yield of the desired compound.

The introduction of heterocyclic rings at the linker was also contemplated, taking profit of the reactivity of the conjugated double bond. Moreover, the resulting products will have a certain analogy with some thiazole and pyrrol derivatives described as PAMs of the $\alpha 7$ nicotinic receptor $[15,30]$. Several attempts to prepare the pyrazol-containing compound by reaction of the chalcone with trimethyl silyl diazomethane failed. However, the preparation of pyrrol derivative $\mathbf{3 2}$ was achieved starting from 3, through the 1,3-dipolar cycloaddition with tosylmethyl isocyanide (TOSMIC) in the presence of sodium hydride as base [31]. Further deprotection with $\mathrm{BBr}_{3}$ led to the final hydroxy derivative $\mathbf{3 3}$ (Figure 6).

\section{Biological evaluation}

- Electrophysiological Studies

Synthesized compounds were evaluated as modulators of $\alpha 7$ nAChRs expressed in Xenopus oocytes. For this purpose, each compound $(10 \mu \mathrm{M})$ was co-applied with ACh $(200 \mu \mathrm{M})$, and the resulting currents were compared to those induced by ACh alone.

As shown in Table 1, the precursor derivatives, with methoxy groups, induced in general current percentage values below $100 \%$ (which is the control value with $200 \mu \mathrm{M}$ ACh alone). Therefore, these compounds act as inhibitors of $\alpha 7$ nAChRs. Maximal inhibition was obtained with compounds 6 (15\% of current observed with ACh alone), $16(26 \%)$ and 13 (29\%). This behavior was also observed for the related tetrasubstituted methoxy-chalcone 4, although the inhibitory capacity was slightly lower (35\%). Reduced analogues 14 and 15, with three OMe groups in ring $A$ and one or two in ring $B$ were poorer inhibitors. Derivatives bearing two OMe groups in ring $A$, and one $\mathrm{OH}$ moiety at ring $\mathrm{B}$ (29 and $\mathbf{3 0}$ ) were very weak inhibitors. Finally, pyrrole derivative $\mathbf{3 2}$ showed only marginal inhibitory ability.

Experiments to determine if these compounds behave as competitive antagonist, competing with ACh for its binding site, or as negative allosteric modulators of the $\alpha 7$ channels were performed.

Figure 7 features a comparison between compound 6, which is the most potent inhibitor, and its chalcone analogue compound 4 . When either of the twowas applied to oocytes expressing human $\alpha 7$ nAChRs, a substantial decrease was observed in AChevoked ionic currents (Figure 7c \& d). Their decay, however, was similar to control currents, so that changes in kinetics were not apparent. Concentration-response relationships (Figure 7e \& f) showed that compound 6 was about 4-fold more potent than compound 4 ( $I C_{50}$ for compounds 6 and 4 was 2.1 and $9.1 \mu \mathrm{M}$, respectively). ACh concentration-response relationships were displaced to the right in the presence of compounds 4 and 6 (Figure $7 \mathrm{~g} \& \mathrm{~h}$ ) ( $\mathrm{EC}_{50}$ for ACh was $176 \mu \mathrm{M}$ in control conditions and $2067 \mu \mathrm{M}$ and $536 \mu \mathrm{M}$ in the presence of compounds 4 and 6, respectively). Although these data do not rule out a competitive mechanism, that would need a 
Schild analysis, negative allosterism is the most probable mechanism given the compounds' structures and the positive allosteric mechanism of structurally similar compounds $\mathbf{7}$ and $\mathbf{3 1}$ (see below).

Besides, effects of the hydroxy substituted compounds in $\alpha 7$ nAChR currents are shown in Table 2 . In general, all propan-1-one derivatives were less effective in potentiating the ACh-evoked currents than the corresponding chalcone analogues. In this series, the most efficient $\alpha 7$ nAChR PAMs were 7 and 31, the propan-1-one analogues corresponding to the most powerful chalcone derivatives $\mathbf{3}$ and $\mathbf{2}$ respectively. Compounds $\mathbf{7}$ and $\mathbf{3 1}$ at $10 \mu \mathrm{M}$ were able to enhance the current induced by ACh by 989 and 666\%, respectively. Therefore, the reduction of the double bond of the chalcone linker resulted in about 2-3 fold less efficient PAMs.

Figure $\mathbf{8}$ features main similarities and differences between compounds $\mathbf{3 1}$ and 7. When either of the two was applied to oocytes expressing human $\alpha 7$ nAChRs, a clear potentiating effect was observed in ACh-evoked ionic currents (Figure 8c \& d), although it was less prominent than the one observed for their chalcone analogues (compounds $\mathbf{2}$ and 3, Figure $\mathbf{8 c} \& \mathbf{d}$ ). Unlike compounds $\mathbf{2}$ and $\mathbf{3}$, the currents decayed relatively fast, so the changes in kinetics were similar to those found for Type I PAMs.

Both compounds $\mathbf{3 1}$ and $\mathbf{7}$ showed similar concentration-dependent effectiveness (Figure $8 \mathbf{e} \& \mathbf{f}$ ) with 15 -fold maximal potentiation of currents evoked by ACh $200 \mu \mathrm{M}$ (see Table 3), but 31 was about two-fold less potent than 7, as deduced from their potentiating $\mathrm{EC}_{50}: 12.9 \mu \mathrm{M}$ and $6.85 \mu \mathrm{M}$ for $\mathbf{3 1}$ and $\mathbf{7}$, respectively (Figure 8e $\& \mathbf{f}$ and Table 3 ). These potencies are comparable to those observed in similar

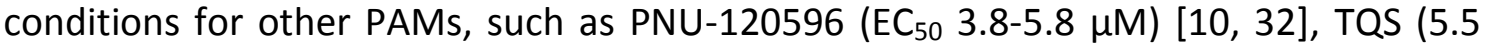
$\mu \mathrm{M})$ [32], and A-86774 (1.1 $\mu \mathrm{M})$ [15]. However, maximum efficacy is probably much higher in our compounds because enhancements were not only larger than the 4 to 6 fold maximal potentiation reported in [32], but were also obtained with a higher ACh concentration ( 0.2 vs. $0.1 \mathrm{mM}$ ), which would have underestimated the potentiating effect. Additionally, comparing the data of $I_{\max }$ and $\mathrm{EC}_{50}$ of propanone 7 with that of the parent compound 3, a slight decrease of efficacy and potency was observed, while compound $\mathbf{3 1}$ displayed lower efficacy but a small increase in potency when compared to chalcone $\mathbf{2}$ (Table $\mathbf{3}$ ).

The potentiating effect was not much dependent on ACh concentration. As shown in Figure $8 \mathrm{~g} \& \mathrm{~h}$, when $10 \mu \mathrm{M}$ of compound 31 or $5 \mu \mathrm{M}$ of compound 7 (concentrations close to the corresponding $\mathrm{EC}_{50}$ ) were co-applied with $\mathrm{ACh}$, the resulting $\mathrm{ACh}$ concentration-response relationships were shifted to the left, as the $\mathrm{ACh}$ $\mathrm{EC}_{50}$ values decreased from $176 \mu \mathrm{M}$ (control) to $38.3 \mu \mathrm{M}$ and $71.3 \mu \mathrm{M}$ in the presence of $\mathbf{3 1}$ and 7, respectively.

Compounds 7 and $\mathbf{3 1}$ were also evaluated for their activity at $\alpha 3 \beta 4$ and $\alpha 4 \beta 2$ nAChRs expressed in Xenopus oocytes, as these two receptor subtypes represent typical representatives of peripheral and central heteromeric receptors, respectively. While the tetrahydroxy derivative $\mathbf{7}$ was able to inhibit the currents induced by ACh at these heteromeric channels (up to 44\%), the trihydroxy analogue $\mathbf{3 1}$ did not exert any action at these receptors (see SD, Table S1). Therefore, $\mathbf{3 1}$ is highly selective towards a7 nAChRs.

Given the importance of $\mathrm{OH}$ groups for our compounds to behave as $\alpha 7 \mathrm{nAChR}$ PAMs, initially we would not have expected activity for the OMe analogues on this receptor, but surprisingly they worked as NAMs. Changes of PAMs to other types of 
allosteric modulators have been previously reported for another family of $\alpha 7 \mathrm{nAChR}$ modulators, upon truly very minor chemical modification, like the exchange of halogens, $S$ to $R$ configuration change, and modification of the number and/or positions of methyl substituents $[9,24]$.

- Analgesic Activity

Agonists and positive allosteric modulators of $\alpha 7 \mathrm{nAChRs}$ display antinociceptive and anti-inflammatory properties in different animal models [7, 18]. For instance, PNU120596 induced analgesic activity by its own or combined with choline in the formalin pain test, and showed anti-allodynic effects in the CCI neuropathic pain model [33-35]. On the other hand, it is reported that different dietary polyphenols, like chlorogenic acid (CGA), resveratrol and quercetin derivatives, have antinociceptive effects on acute, inflammatory and neuropathic pain models [36-38], although their mechanisms of action are not totally understood.

We have previously studied PNU-120596 and chalcone $3(10 \mathrm{mg} / \mathrm{Kg})$ for the reduction of thermal and mechanical hyperalgesia resulting from inflammation induced by complete Freund's adjuvant (CFA). Both showed antinociceptive effects in the mechanical hyperalgesia test, and lacked significant activity in the thermal assay [25]. Main peak of activity was at 2h for PNU-120596 and at $30 \mathrm{~min}$ for chalcone 3, probably due to different pharmacokinetic drug clearance.

When compounds $\mathbf{7}$ and $\mathbf{3 1}$ were tested for their antihyperalgesic properties in the above mentioned mechanical test, very different results were obtained. While no signs of antinociceptive activity were observed for tetrahydroxy derivative 7 (Figure 9, left), the trihydroxy analogue $\mathbf{3 1}$ (Figure 9, right) exhibited analgesic activity comparable to that demonstrated by PNU-120596 [25]. Compound 31 displayed significant activity at $1 \mathrm{~h}$ and the maximum peak at $2 \mathrm{~h}$ after the injection, like PNU derivative. The differences between $\mathbf{7}$ and $\mathbf{3 1}$ in in vivo experiments could be accounted for by distinct mechanisms, including the lack of selectivivity of the former, the stronger effect on desensitization of the latter, and their different pharmacokinetic profiles, as commented in the next section.

- Physicochemical Properties and Preliminary In Vitro ADME (AdministrationDistribution-Metabolism-Excretion) Profile.

To get an insight on the potential of this series of compounds for further progress in the drug development process, we characterized their pharmacokinetic (PK) features. Some theoretical and experimental PK parameters of propan-1-one analogues 7 and 31, showing the best $\alpha 7$ nACh activity, are shown in Table 4, and compared with those of the parent chalcone 3 . They include physicochemical properties such as molecular weight (MW), calculated lipophilicity (CLogP), and polar surface area (PSA). In addition, a short in vitro ADME profile for the three compounds was performed, including solubility in simulated fluids, ability to bind to plasma proteins, permeability in Caco-2 cells, and metabolism in human liver microsomes.

Taking into account the calculated physicochemical parameters, the low MW (<300 Da) and the calculated CLogP (2.51-2.71) and PSA (77-97) values for the three compounds were suggestive of probable good oral absorption (Table 4).

From the in vitro PK data, compound $\mathbf{3}$ showed quite limited aqueous solubility, especially at $\mathrm{pH}>\mathbf{7}$, but propan-1-ones $\mathbf{7}$ and $\mathbf{3 1}$ are more soluble in the three 
simulated fluids. While $\mathbf{3}$ is a totally planar molecule that could stack to form aggregates, the reduction of the double bond necessarily break the planarity, thus increasing solubility in $\mathbf{7}$ and $\mathbf{3 1}$. The three compounds bound very strongly to plasma proteins (> 95\%), but the experimental permeability in Caco-2 cells was clearly different among them. The values for compounds $\mathbf{3}$ and $\mathbf{7}$ indicated a moderate-to-low permeation and a certain probability of efflux. For compound $\mathbf{3}$, this low permeability could be due, at least in part, to the quite limited aqueous solubility in the different fluids, but other factors should be responsible for the poor value of $\mathbf{7}$. Probably, the low permeability of compound $\mathbf{7}$ is the main responsible of its inactivity in the analgesia in vivo test. However, the permeability increased by 6 - and 10 -fold in the case of the in vivo active compound $\mathbf{3 1}$ with respect to $\mathbf{3}$ and $\mathbf{7}$, respectively. The lower molecular weight and the PSA value could be behind the higher permeability. In relation to microsomal metabolic labilities, all compounds showed acceptable to good half-life values for an initial lead compound, but their apparent intrinsic clearances were quite high, indicating low hepatic metabolic stability. The 19 min difference in $\mathrm{t}_{1 / 2}$ between $\mathbf{3}$ and $\mathbf{7}$ indicates that the chalcone double bond is a labile point for metabolic modification, probably through oxidation. Similarly, the lower half-life of 31, lacking the $2-\mathrm{OH}$ group, when compared to $7\left(\Delta \mathrm{t}_{1 / 2}=-24 \mathrm{~min}\right)$ is an indicative of another metabolically active position. All these information could help us in designing further modifications around the structure of compounds 3, 7 and $\mathbf{3 1}$ to improve essential PK properties, while maintaining the potency as $\alpha 7$ nAChR PAMs.

\section{- Antioxidant Capacity}

The antioxidant properties of many hydroxy-containing natural products are well documented, and it is suspected that this property is behind many of their beneficial effects on health, expanding from neuroprotective and antiinflammatory effects to the prevention of cancer and cardiovascular diseases [39-42]. Hydroxyl groups of phenols are one of the key moieties to enhance antioxidant activity due to its easy conversion to phenoxy radicals through a hydrogen transfer mechanism [43]. As our allosteric $\alpha 7$ nACh modulators bear three or four hydroxy groups on their structures, we decided to evaluate their possible antioxidant activity. For this purpose, the oxygen radical scavenging capacity of compounds 3, $\mathbf{7}$ and $\mathbf{3 1}$ was measured by the ORAC assay (Table 5). All compounds exhibited strong radical scavenging activities, similar or even higher than those described for well-known flavonoids [44, 45]. According to these results, the antioxidant activity of our compounds is dependent on the number of $\mathrm{OH}$ groups in the molecule and on the linker joining the phenyl rings. Thus, for tetrahydroxy derivatives, the oxygen radical scavenging capacity is higher for the reduced compound $\mathbf{7}$ than for the alkene-counterpart 3 . Between reduced compounds, the ORAC value is better for the tetra- than for the trihydroxy derivative (7 > 31).

The combination of antioxidant properties and allosteric potentiation of $\alpha 7$ nAChRs in a single molecule is a new trend in the therapy of Alzheimer disease (AD). This occurs in the case of galantamine [46], a marketed drug for AD treatment, and epigallocatechin gallate that acts as a neuroprotecting agent against $A \beta$ toxicity [47]. Therefore, the opportunity of using our compounds to tackle $A D$ on multiple fronts is open. 


\section{Experimental}

General synthetic and analytical chemistry methods, as well as the characterization of new compounds not described in this section are included in the Supporting Information.

\section{- Chemistry}

- General procedure for the preparation of 1,3-diphenyl-1-propanones: To a solution of the corresponding chalcone $(0.30 \mathrm{mmol})$ in $\mathrm{MeOH}(30 \mathrm{~mL})$ and diphenylsulfide $(0.003 \mathrm{mmol}), \mathrm{Pd} / \mathrm{C} \quad 10 \% \quad(10 \%$ weight $)$ was added. After hydrogenation, at room temperature and 20 psi during $24 \mathrm{~h}$, the catalyst was filtered off, the solvent evaporated under vacuum, and the residue purified by flash chromatography as indicated.

1-(2',5'-Dimethoxyphenyl)-3-(2,4-dimethoxyphenyl)-1-propanone (6)

White amorphous solid, $79 \mathrm{mg}(78 \%$ yield). Eluent: 0 to $25 \%$ gradient of EtOAc in hexane. HPLC-MS (Sunfire): $t_{R}=10.00$ min (10 min gradient: 80 to $95 \%$ of $A$ in B). ${ }^{1} \mathrm{H}$ NMR (500 MHz, DMSO), $\delta: 2.75\left(\mathrm{t}, 2 \mathrm{H}, \mathrm{H}_{\beta}\right), 3.11\left(\mathrm{t}, 2 \mathrm{H}, \mathrm{H}_{\alpha}\right), 3.72(\mathrm{~s}, 6 \mathrm{H}, \mathrm{OMe}), 3.75$ (s, $3 \mathrm{H}, \mathrm{OMe}), 3.79(\mathrm{~s}, 3 \mathrm{H}, \mathrm{OMe}), 6.42(\mathrm{dd}, J=8.2,2.4 \mathrm{~Hz}, 1 \mathrm{H}, 5-\mathrm{H}), 6.50(\mathrm{~d}, J=2.4 \mathrm{~Hz}, 1 \mathrm{H}$, $3-\mathrm{H}), 7.01(\mathrm{~d}, J=8.4 \mathrm{~Hz}, 1 \mathrm{H}, 6-\mathrm{H}), 7.03\left(\mathrm{~m}, 1 \mathrm{H}, 4^{\prime}-\mathrm{H}\right), 7.09\left(\mathrm{~m}, 2 \mathrm{H}, 3^{\prime}-\mathrm{H}\right.$ y $\left.6^{\prime}-\mathrm{H}\right) \mathrm{ppm} .{ }^{13} \mathrm{C}$ NMR (125 MHz, DMSO), $\delta: ~ 24.1\left(C_{\beta}\right), 43.3\left(C_{\alpha}\right), 55.1$ (OMe), 55.3 (OMe), 55.5 (OMe), 56.2 (OMe), 98.3 (C-3), 104.3 (C-5), 113.5 (C-6'), 113.9 (C-3'), 119.0 (C-4'), 121.0 (C-1), 128.5 (C-1'), 129.8 (C), 129.8 (C-6), 152.2 (C), 157.9 (C), 159.0 (C), 201.1 (CO) ppm. MS $(\mathrm{ESI}+): \mathrm{m} / \mathrm{z} 331.4(\mathrm{M}+\mathrm{H})^{+}, 353.5(\mathrm{M}+\mathrm{Na})^{+}$.

\section{3-(2,4-Dimethoxyphenyl)-1-(3'-methoxyphenyl)-1-propanone (16)}

Prepared following the general method B. Colorless oil, $79 \mathrm{mg}$ (90\% yield). Eluent: 0 to $30 \%$ gradient of EtOAc in hexane. HPLC-MS (Sunfire): $\mathrm{t}_{R}=8.95$ (10 min gradient: 15 to $95 \%$ of $A$ in B). ${ }^{1} \mathrm{H}$ NMR (500 MHz, DMSO), $\delta: 2.81\left(\mathrm{t}, J=7.6 \mathrm{~Hz}, 2 \mathrm{H}, \mathrm{H}_{\beta}\right), 3.20(\mathrm{t}, J=7.6$ $\mathrm{Hz}, 2 \mathrm{H}, \mathrm{H}_{\alpha}$ ) 3.72 (s, 3H, OMe), $3.76(\mathrm{~s}, 3 \mathrm{H}, \mathrm{OMe}), 3.81$ (s, 3H, OMe), 6.43 (dd, $J=8.2$, $2.4 \mathrm{~Hz}, 1 \mathrm{H}, \mathrm{H}-5), 6.52(\mathrm{~d}, J=2.4 \mathrm{~Hz}, 1 \mathrm{H}, \mathrm{H}-3), 7.07$ (d, J= $8.2 \mathrm{~Hz}, 1 \mathrm{H}, \mathrm{H}-6), 7.20$ (ddd, $J=$ 8.2, 2.7, $\left.0.8 \mathrm{~Hz}, 1 \mathrm{H}, \mathrm{H}-4^{\prime}\right), 7.40-7.46\left(\mathrm{~m}, 2 \mathrm{H}, \mathrm{H}-5^{\prime}\right.$ and $\left.\mathrm{H}-2^{\prime}\right), 7.55(\mathrm{dd}, J=7.8,1.3 \mathrm{~Hz}, 1 \mathrm{H}$, H-6') ppm. ${ }^{13} \mathrm{C}$ NMR (125MHz, DMSO), $\delta: 24.2\left(\mathrm{C}_{\beta}\right), 38.4\left(\mathrm{C}_{\alpha}\right), 55.1$ (OMe), $55.3(2 \mathrm{C}$, OMe), 98.3 (C-3), 104.4 (C-5), 112.3 (C-6'), 119.1 (C-4'), 120.4 (C), 120.9 (C-5'), 129.9 (C-6, C-2'), 138.0 (C), 157.9 (C), 159.1 (C), 159.4 (C), 199.4 (CO) ppm. MS (ESI+): m/z $301.4(\mathrm{M}+\mathrm{H})^{+}, 323.4(\mathrm{M}+\mathrm{Na})^{+}$.

- General procedure for the deprotection of methoxy substituted compounds: To a previously cooled solution $\left(0^{\circ} \mathrm{C}\right)$ of the corresponding methoxy substituted compound $(0.60 \mathrm{mmol})$ in dried DCM $(15 \mathrm{~mL})$, a $1 \mathrm{M}$ solution of $\mathrm{BBr}_{3}$ in DCM (2 equiv for each MeO- group plus 2 more equiv for every group containing a potentially basic $\mathrm{N}$ or O) was slowly added under Ar atmosphere. After stirring 24-48 $\mathrm{h}$ at room temperature under $\mathrm{Ar}, \mathrm{H}_{2} \mathrm{O}$ was added to the reaction mixture. The solid precipitate formed was separated by filtration, and washed with $\mathrm{H}_{2} \mathrm{O}$ and DCM. In the cases when no precipitate was observed, the product was extracted with EtOAc. The organic 
extracts were washed with $\mathrm{H}_{2} \mathrm{O}$ and brine, dried over $\mathrm{Na}_{2} \mathrm{SO}_{4}$ and then evaporated. The crude product was purified as indicated in each case.

1-(2',5'-Dihydroxyphenyl)-3-(2,4-dihydroxyphenyl)-1-propanone (7)

Reddish solid, $50 \mathrm{mg}$ ( $27 \%$ yield), $\mathrm{mp} 150-152^{\circ} \mathrm{C}$. Purification by reverse phase flash chromatography. (Eluent: gradient from 2 to $30 \%$ of EtOAc in hexane). HPLC (Sunfire): $\mathrm{t}_{R}=6.90 \mathrm{~min}$ (10 min gradient: 15 to $95 \%$ of $\mathrm{A}$ in $\left.\mathrm{B}\right) .{ }^{1} \mathrm{H}$ NMR (500 MHz, DMSO) $\delta: 2.72$ $\left(\mathrm{t}, J=7.5 \mathrm{~Hz}, 2 \mathrm{H}, \mathrm{H}_{\beta}\right), 3.16\left(\mathrm{t}, J=7.5 \mathrm{~Hz}, 2 \mathrm{H}, \mathrm{H}_{\alpha}\right), 6.12(\mathrm{dd}, J=8.1,2.4 \mathrm{~Hz}, 1 \mathrm{H}, 5-\mathrm{H}), 6.27$ (d, $J=2.4 \mathrm{~Hz}, 1 \mathrm{H}, 3-\mathrm{H}), 6.80\left(\mathrm{~d}, J=8.8 \mathrm{~Hz}, 1 \mathrm{H}, 3^{\prime}-\mathrm{H}\right), 6.84(\mathrm{~d}, J=8.1 \mathrm{~Hz}, 1 \mathrm{H}, 6-\mathrm{H}), 6.97$ (dd, $\left.J=8.8,2.9 \mathrm{~Hz}, 1 \mathrm{H}, 4^{\prime}-\mathrm{H}\right), 7.20\left(\mathrm{~d}, J=2.9 \mathrm{~Hz}, 1 \mathrm{H}, 6^{\prime}-\mathrm{H}\right), 9.04(\mathrm{~s}, 1 \mathrm{H}, \mathrm{OH}), 9.26(\mathrm{~s}, 2 \mathrm{H}$, $\mathrm{OH}), 11.34(\mathrm{~s}, 1 \mathrm{H}, \mathrm{OH}) \mathrm{ppm} .{ }^{13} \mathrm{C} \mathrm{NMR}(125 \mathrm{MHz}, \mathrm{DMSO}) \delta: 24.5\left(\mathrm{C}_{\beta}\right), 39.5\left(\mathrm{C}_{\alpha}\right.$ together with the DMSO signal), 102.5 (C-3), 106.0 (C-5), 114.7 (C-6'), 117.4 (C-1), 118.5 (C-3'), 120.1 (C-1'), 124.3 (C-4'), 130.2 (C-6), 149.5 (C), 153.8 (C), 155.9 (C), 156.6 (C), 205.6 (CO) ppm. MS (ES+): $\mathrm{m} / z 275.6(\mathrm{M}+\mathrm{H})^{+}$. HRMS (ESI+) $\mathrm{m} / z$ calculated for $\mathrm{C}_{15} \mathrm{H}_{14} \mathrm{O}_{5}$ $(\mathrm{M}+\mathrm{H})^{+}$275.0914, found 275.0917 .

1-(2',5'-dihydroxyphenyl)-3-(4-hydroxyphenyl)-1-propanone (31)

Solid, $94 \mathrm{mg}$ ( $72 \%$ yield), $\mathrm{mp} 105-108^{\circ} \mathrm{C}$. HPLC (Sunfire): $\mathrm{t}_{R}=7.71 \mathrm{~min}$ (10 min gradient: 15 to $95 \%$ of $A$ in B). ${ }^{1} \mathrm{H}$ NMR (500 MHz, DMSO) $\delta: 2.80\left(\mathrm{t}, J=7.7 \mathrm{~Hz}, 2 \mathrm{H}, \mathrm{H}_{\beta}\right), 3.26(\mathrm{t}, J=$ $\left.7.7 \mathrm{~Hz}, 2 \mathrm{H}, \mathrm{H}_{\alpha}\right), 6.66(\mathrm{~d}, J=8.4 \mathrm{~Hz}, 2 \mathrm{H}, 3-\mathrm{H}$ and $5-\mathrm{H}), 6.80\left(\mathrm{~d}, J=8.9 \mathrm{~Hz}, 1 \mathrm{H}, 3^{\prime}-\mathrm{H}\right), 6.97$ (dd, $\left.J=8.9,3.0 \mathrm{~Hz}, 1 \mathrm{H}, 4^{\prime}-\mathrm{H}\right), 7.05(\mathrm{~d}, J=8.4 \mathrm{~Hz}, 2 \mathrm{H}, 2-\mathrm{H}$ and $6-\mathrm{H}), 7.19(\mathrm{~d}, J=3.0 \mathrm{~Hz}, 1 \mathrm{H}$, $\left.6^{\prime}-\mathrm{H}\right), 9.17(\mathrm{~s}, 1 \mathrm{H}, \mathrm{OH}), 11.25(\mathrm{~s}, 1 \mathrm{H}, \mathrm{OH}) \mathrm{ppm} .{ }^{13} \mathrm{C}$ NMR (125 MHz, DMSO) $\delta: 28.8\left(\mathrm{C}_{\beta}\right)$, $41.0\left(C_{\alpha}\right), 114.7\left(C-6^{\prime}\right), 115.1$ (C-3, C-5), 118.4 (C-3'), 120.2 (C-4'), 124.1 (C-1'), 129.2 (C2, C-6), 131.0 (C-1), 149.4 (C), 153.5 (C), 155.5 (C), 204.8 (CO) ppm. MS (EI $\left.{ }^{+}\right): m / z 259.2$ $(\mathrm{M}+\mathrm{H})^{+}$. HRMS $(\mathrm{ESI}+) \mathrm{m} / z$ calculated for $\mathrm{C}_{15} \mathrm{H}_{14} \mathrm{O}_{4}(\mathrm{M}+\mathrm{H})^{+}$259.09649, found 259.09611 .

\section{- Biological procedures}

- Oocyte Expression and Electrophysiological Studies.

All human nAChR cDNAs were cloned in derivatives of the pSP64T vector containing part of the pBluescript polylinker. Capped mRNA was synthesized in vitro using SP6 RNA polymerase, the mMESSAGE-mMACHINE kit from Ambion (Thermo Fisher Scientific, Madrid, Spain) and the pSP64T derivatives mentioned above. Defoliculated Xenopus laevis oocytes were injected with $5 \mathrm{ng}$ of each subunit cRNA in $50 \mathrm{~nL}$ of sterile water. All experiments were performed within 2-3 days after cRNA injection. Unless otherwise specified, compounds were pre-applied in the bath for $2 \mathrm{~min}$ and then coapplied with ACh through a pipette held very close to the oocyte for fast application. Functional expression of each receptor was estimated as the peak ionic current evoked by $0.6 \mathrm{~s}$ application of $0.2 \mathrm{mM} \mathrm{ACh}$ at $-80 \mathrm{mV}$. All experiments were performed at $22^{\circ} \mathrm{C}$. Current records were measured with Clampfit 10.0 (MDS Analytical Technologies, Sunnyvale, CA, USA). Normalized peak currents were obtained by dividing the maximum value of the current obtained in the presence of compound by the maximum value of the current obtained in control conditions. Dose-response curves for the peak current obtained with ACh were fitted to the Hill equation: Normalized current $=I_{\max } /\left(1+\left(E_{50} /[A C h]\right)^{\mathrm{nH}}\right)$. Data are expressed as mean $\pm \mathrm{SEM}$.

- Analgesic assay. 
Male Wistar rats (250-300 g) were obtained from Janvier France. All experiments were approved by the Institutional Animal and Ethical Committee of the Universidad Miguel Hernandez where experiments were conducted and they were in accordance with the guidelines of the Economic European Community and the Committee for Research and Ethical Issues of the International Association for the Study of Pain. All parts of the study concerning animal care were performed under the control of veterinarians.

CFA emulsion ( $1: 1$ oil/saline, $0.5 \mathrm{mg} / \mathrm{mL}$ ) was injected into the plantar surface $(50 \mu \mathrm{L})$ of the left hind paw of rats [48]. Compounds were administered at $10 \mathrm{mg} / \mathrm{kg}$ i.v. $24 \mathrm{~h}$ after CFA injection.

The mechanical allodynia was monitored $24 \mathrm{~h}$ after CFA injection and up to $4 \mathrm{~h}$ after administering the compounds. Paw withdrawal latency to mechanical stimulation was assessed with an automated testing device consisting of a steel rod that is pushed against the plantar surface of the paw with increasing force until the paw is withdrawn (Dynamic Plantar Aesthesiometer; Ugo Basile). The maximum force was set at $50 \mathrm{~g}$ to prevent tissue damage and the ramp speed was $2.5 \mathrm{~g} / \mathrm{s}$. Rats were placed in test cages with a metal grid bottom. They were kept in the test cages for 30-40 min to allow accommodation. The paw withdrawal latency was obtained as the mean of 3 consecutive assessments at each time point (at least $10 \mathrm{~s}$ between repeated measurements of the same paw).

- Oxygen Radical Absorbance Capacity (ORAC) Experiment.

The ORAC assay was performed following Ou et al. [49], as modified by Davalos et al. [44]. All samples and reagents were dissolved in phosphate buffer (75 mM; pH 7.4). The reaction was performed in a final volume of $200 \mu \mathrm{l}: 20 \mu \mathrm{l}$ test samples or $20 \mu \mathrm{l}$ Trolox solutions $(0.2-2 \mathrm{nM}), 120 \mu$ fluorescein solution $(1.17 \mathrm{mM})$ and $60 \mu \mathrm{l}$ 2,2'-azobis-(2-methylpropionamidine) dihydrochloride (AAPH) 1.3\% solution (all from Sigma Aldrich) were added to the wells of a black 96-well plate. The fluorescence was recorded at $40{ }^{\circ} \mathrm{C}$ every $55 \mathrm{~s}$ for 95 min using a fluorimeter (SpectraMax M2; Molecular Devices, California, USA), with excitation and emission wavelengths of 480 and 520 $\mathrm{nm}$, respectively. All samples were tested in triplicate. ORAC values were expressed as $\mu \mathrm{mol}$ Trolox equivalents/ $\mu \mathrm{mol}$ of pure compound.

\section{Conclusion}

A series of 1,3-diphenylpropan-1-ones have been synthesized and evaluated for their activity at $\alpha 7$ nAChRs. Remarkably, the modulation of these nicotinic channels goes in opposite directions depending on the phenyl ring substituents. Thus, while OMesubstituted derivatives inhibited the activation of $\alpha 7 \mathrm{nAChRs}$ by ACh (probably acting as NAMs), most analogues with $\mathrm{OH}$ substitutions are type I PAMs. Compounds $\mathbf{7}$ and 31 display the best potency and efficacy profiles within the series, and the latter is highly selective against $\alpha 3 \beta 4$ and $\alpha 4 \beta 2$ nAChRs. In in vivo experiments, using an inflammatory pain model of mechanical hyperalgesia, compound $\mathbf{3 1}$ showed significant antinociceptive effects, comparable to that displayed by PNU-120596, while the tetrahydroxy analogue 7 was inactive. The about 10-fold lower permeability of compound 7, compared to 31, could explain its lack of activity in the in vivo test. In addition to the above indicated in vitro and in vivo activities, these compounds displayed remarkable antioxidant properties in ORAC experiments. Compounds within 
this 1,3-diphenylpropan-1-one series could serve to restore the impaired sensory gating and cognitive deficits in $A D$, because of their cholinergic connection. Also by reason of the fact that oxidative stress and plaque deposition, associated with chronic inflammation in the brain, are key events in $A D$ pathogenesis and progression. The multiactivity and pharmacokinetic profile of compound $\mathbf{3 1}$ could place it as a good starting point to improved analogues having potential longer advance in the course of the drug development process. Work in this direction is underway in our labs.

\section{Future perspective}

Alpha7 nicotinic acetylcholine receptor ( $\alpha 7 \mathrm{nAChR})$ is an important player of the cholinergic nerve system in the brain, associated with the anti-inflammatory pathway of the parasympathetic nervous system. Experimental models indicated that vagal nerve stimulation attenuates the production of proinflammatory cytokines, inhibiting the inflammatory process, probably through the $\alpha 7 \mathrm{nAChRs}$. This provides a rationale for the utility of $\alpha 7 \mathrm{nAChR}$ agonists and PAMs in the treatment of inflammatory pain.

Both central and peripheral $\alpha 7 n A C h R$ has been involved in changes in body weight associated to nicotine. As important peripheral mediators of chronic inflammation, $\alpha 7 n A C h R s$ are also key contributors to obesity. Recent studies identify links between $\alpha 7 n A C h R$ expression and obesity, insulin resistance, and diabetes. Therefore, this nicotinic channel may also be a useful therapeutic target to treat and manage obesity. In addition, the reduction of the $\alpha 7 \mathrm{nAChR}$ function has been identified as a potential mechanism for elevated tobacco consumption and consequently, the activation of $\alpha 7$ nAChRs could be explored for tobacco cessation therapy.

The $\alpha 7-n A C h R$ receptors are expressed by macrophages and its expression is crucial for the anti-inflammatory effect of vagal nerve signaling. Nicotine exerts antiinflammatory effects on macrophages that can be counteracted by selective $\alpha 7$ antagonists.[50, 51] Selective $\alpha 7 \mathrm{nAChR}$ agonists have proven effective in reducing macrophage cytokine production and inflammation in animal models of pancreatitis,[52] dextran sulfate sodium (DSS)-induced colitis[53] and intestinal ileus. [54] Nicotine has been tested in clinical trials as a treatment for inflammatory diseases such as ulcerative colitis, but the therapeutic potential of this mechanism is limited by the collateral toxicity of nicotine, which support the needed of designing new molecules as positive allosteric modulators of $\alpha 7 \mathrm{nAChR}$ that would have antiinflammatory effects while eluding collateral toxicity.

Finally, $\alpha 7$ nicotinic channels are also implicated in the modulation of different cognitive functions such as attention, and working and episodic memory. Increasing preclinical and clinical evidences suggest that $\alpha 7 \mathrm{nAChR}$ activation is of promising therapeutic value for the treatment of cognitive impairment associated with Alzheimer's disease (AD) and schizophrenia.

Nowadays, there are no approved drugs that work through this receptor subtype, although several are at different stages of clinical development. Recent promising approaches are based on the use of positive allosteric modulators, PAMs, due to their several advantages over direct agonists. However, their effects, regarding inflammatory pain, nicotine dependence, obesity and cognitive functions during neurodegenerative diseases, have not been totally characterized. The present findings confirm and extend the observations indicating that the positive allosteric modulation of $\alpha 7-n A C h R s$ displays antinociceptive effects in models of inflammatory pain. The 
antioxidant activity of our compounds could represent an additional advantage for studying their potential applications to diseases triggered by multiple mechanisms, like obesity and AD.

All the information that is being generated by preclinical and clinical studies on this subject will provide a deeper understanding of the nicotinic pathway in the indicated pathological conditions, and could result in new $\alpha 7$ nAChR-targeted therapies for treating them.

\section{Acknowledgements}

This work was supported by the Spanish MINECO: CSD2008-00005, The Spanish Ion Channel Initiative-CONSOLIDER INGENIO 2010, SAF2011-22802 and BFU2012-39092C02. The Instituto de Neurociencias is a "Centre of Excellence Severo Ochoa".

We thank Susana Cámara Garrido for her assistance in the synthesis of some starting compounds and Susana Gerber for technical assistance. BBP thanks the CSIC for a predoctoral fellowship (JAE-Predoc from Junta para la Ampliación de Estudios, cofinanced by FSE).

\section{Supplementary data}

Synthetic experimental procedures and characterization of new compounds. Activities of compounds $\mathbf{7}$ and 31 at other nAChRs.

\section{Executive summary}

- The allosteric modulation of $\alpha 7 \mathrm{nAChRs}$ represents promising therapeutic strategies for the treatment of inflammatory pain, and cognitive impairments, among other pathological conditions.

- OMe-substituted 1,3-diphenylpropan-1-ones are able to inhibit the activation of $\alpha 7$ nAChRs.

- Hydroxy-substituted 1,3-diphenylpropan-1-one analogues are potent and selective $\alpha 7$ nAChR positive allosteric modulators.

- Compound 31 behaves as a potent and selective $\alpha 7$ nAChR PAM and displays antinociceptive activity in an inflammatory pain model.

- Its antioxidant activity, combined with the properties at the nicotinic pathway, predict future potential for multimechanism-triggered diseases, like obesity and AD. 
<smiles>O=C(/C=C/c1ccc(O)cc1)c1ccc(O)cc1O</smiles>

Isoliquiritigenin, 1<smiles>O=C(/C=C/c1ccc(O)cc1)c1cc(O)ccc1O</smiles>

2<smiles>O=C(/C=C/c1ccc(O)cc1O)c1cc(O)ccc1O</smiles>

3

Figure 1. Hydroxychalcones $\alpha 7$ nAChRs PAMs<smiles>COc1ccc(/C=C/C(=O)c2cc(OC)ccc2OC)c(OC)c1</smiles>

(A)<smiles>COc1ccc(CCC(O)c2cc(OC)ccc2OC)c(OC)c1</smiles>

(B)<smiles>COc1ccc(CCC(=O)c2cc(OC)ccc2OC)c(OC)c1</smiles>

(C)<smiles>O=C(CCc1ccc(O)cc1O)c1cc(O)ccc1O</smiles>

Figure 2: Hydrogenation of chalcone 4. Reagents and conditions: $(A) \mathrm{H}_{2}, \mathrm{Pd}$ on $\mathrm{C}$, methanol, r.t., 4h; (B) $\mathrm{H}_{2}$, $\mathrm{Pd}$ on $\mathrm{C}, \mathrm{Ph}_{2} \mathrm{~S}$, methanol, r.t., 24h; (C) boron tribromide, dichloromethane, r.t., Ar atmos, r.t., $24 \mathrm{~h}$. 


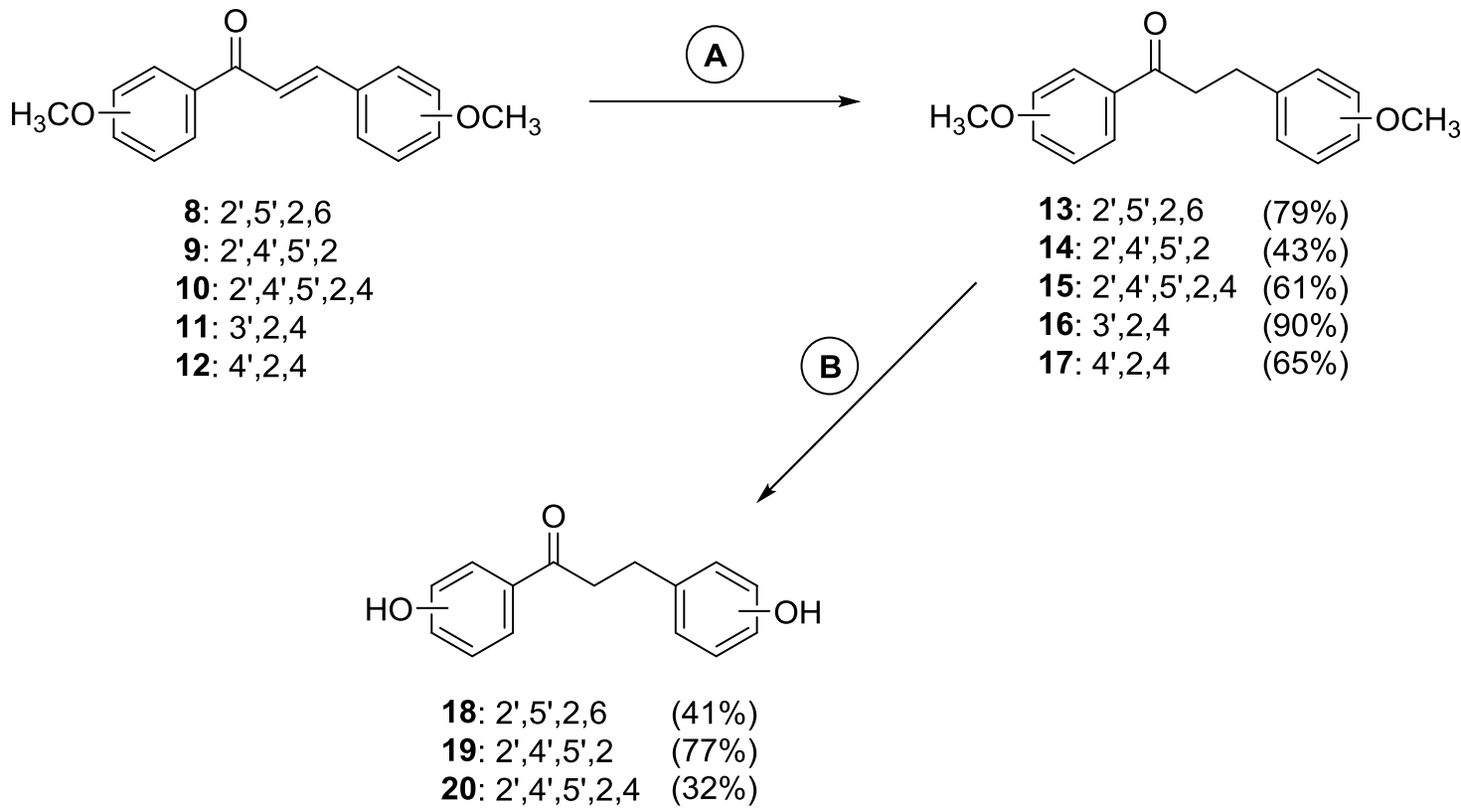

Figure 3: Preparation of polyhydroxy propan-1-ones. Reagents and conditions: $(A) \mathrm{H}_{2}$, $\mathrm{Pd}$ on $\mathrm{C}, \mathrm{Ph}_{2} \mathrm{~S}$, methanol, r.t., 24h; (B) boron tribromide, dichloromethane, r.t., $\mathrm{Ar}$ atmos, r.t., 24-48h.<smiles>O=C(/C=C/c1ccc(O)cc1O)c1ccccc1</smiles>

21: 2

22: 3 '

23: $4^{\prime}$<smiles>O=C(CCc1ccc(O)cc1O)c1ccccc1</smiles>

24: $2^{\prime}(23 \%)$

25: $3^{\prime}(22 \%)$

26: $4^{\prime}(38 \%)$

Figure 4. Synthesis of diphenylpropan-1-ones monohydroxylated in ring $A$. Reagents and conditions: (A) $\mathrm{H}_{2}, \mathrm{Pd}$ on $\mathrm{C}, \mathrm{Ph}_{2} \mathrm{~S}$, methanol, r.t., $24 \mathrm{~h}$. 


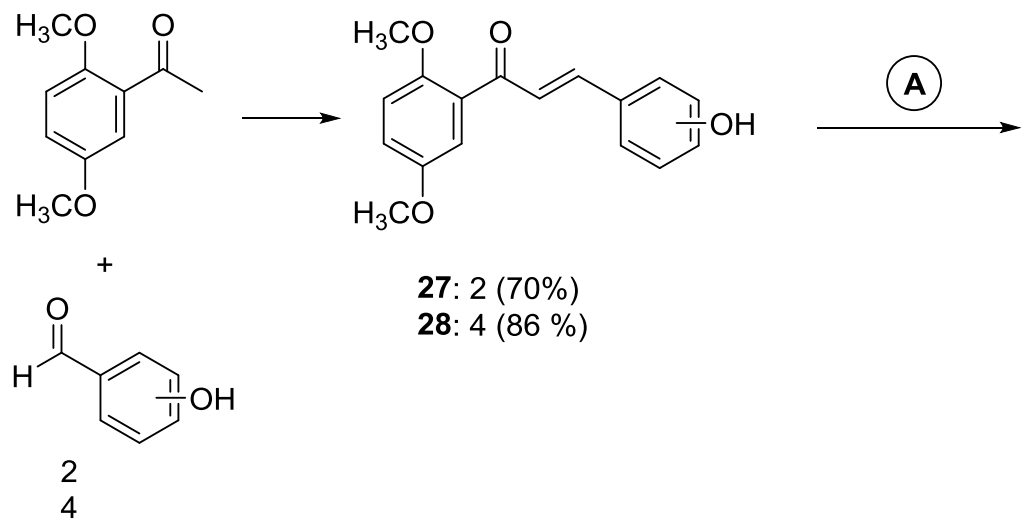

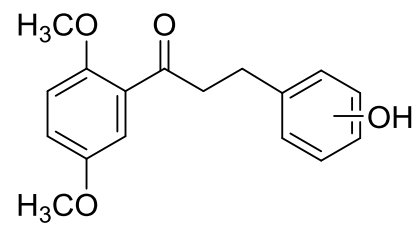

29: $2(89 \%)$

30: $4(48 \%)$

\section{(B)}<smiles>O=C(CCc1ccc(O)cc1)c1cc(O)ccc1O</smiles>

$31(72 \%)$ obtained from 30

Figure 5. Preparation of propan-1-ones monohydroxylated in ring $\mathbf{B}$. Reagents and conditions: (A) $\mathrm{H}_{2}, \mathrm{Pd}$ on $\mathrm{C}, \mathrm{Ph}_{2} \mathrm{~S}$, methanol, r.t., 24h; (B) boron tribromide, dichloromethane, r.t., Ar atmos, r.t., $24 \mathrm{~h}$.<smiles>COc1ccc(OC)c(C(=O)/C=C/c2ccc(OC)c(OC)c2)c1</smiles>

Figure 6. Synthesis of pyrrol derivative 33. Reagents and conditions: (A) ptoluenesulfonylmethyl isocyanide (Tosmic), sodium hydride, diethyl ether, dimethylsulfoxide, r.t., 24h; (B) boron tribromide, dichloromethane, r.t., Ar atmos, r.t., $24 \mathrm{~h}$. 
a)<smiles>COc1ccc(C=CC(=O)c2cc(OC)ccc2OC)c(OC)c1</smiles>

C)

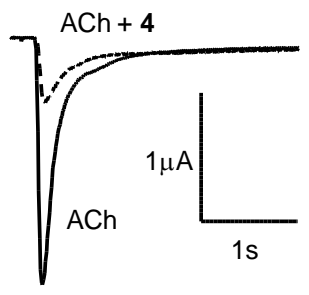

e)

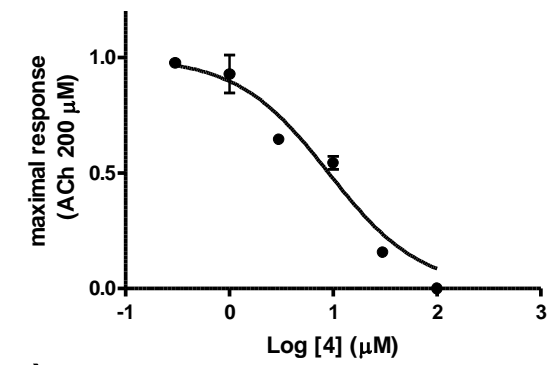

g)

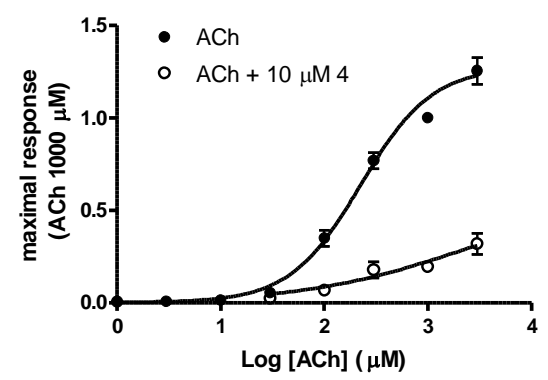

b)<smiles>COc1ccc(CCC(=O)c2cc(OC)ccc2OC)c(OC)c1</smiles>

d)

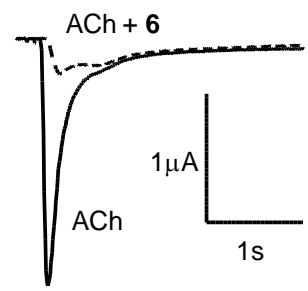

f)

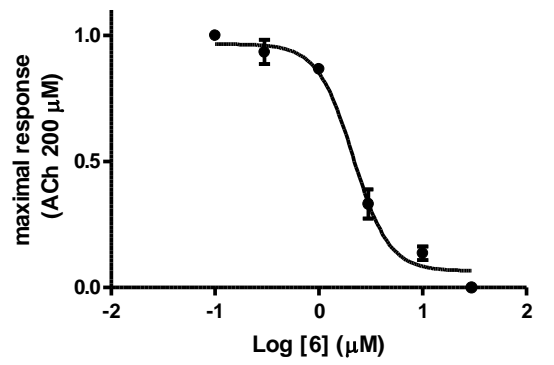

h)

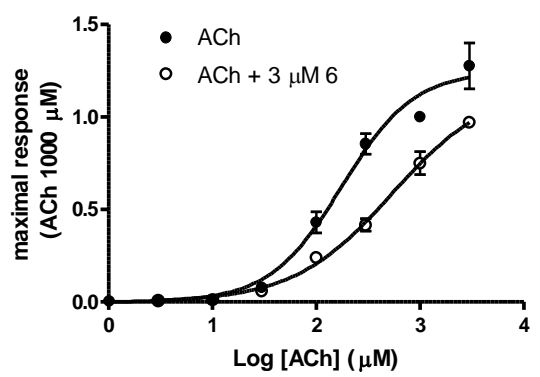

Figure 7. Comparison between compounds 4 (left panels) and 6 (right panels). a-b) Chemical structure of the tetrasubstituted methoxy-chalcone $\mathbf{4}$, and its reduced analogue 6. c-d) lonic currents recorded in representative oocytes expressing human $\alpha 7$ nAChRs. Currents were evoked by $600 \mathrm{~ms}$ applications of ACh $200 \mu \mathrm{M}$ in the absence (continuous line) and in the presence (dotted line) of $10 \mu \mathrm{M}$ of $\mathbf{4}$ or $\mathbf{6}$. All currents were recorded at a holding potential of $-80 \mathrm{mV}$. e-f) Concentration-response relationships for the inhibiting effect of 4 and 6 co-applied with ACh $200 \mu \mathrm{M}$. Continuous lines represent the fit to the Hill equation resulting in $\mathrm{IC}_{50}$ values of $9.1 \mu \mathrm{M}$ and $2.1 \mu \mathrm{M}$ for 4 and 6, respectively. g-h) Acetylcholine concentration-response relationships in the absence (closed circles) and in the presence (open circles) of 10 $\mu \mathrm{M}$ of 4 or $3 \mu \mathrm{M}$ of 6 . These concentrations were chosen because they are close to their respective $I C_{50}$ values. All data were normalized to the response obtained by $A C h$ $1 \mathrm{mM}$ in control conditions. Continuous lines represent fits to Hill equations. 
a)<smiles>O=C(CCc1ccc(O)cc1)c1cc(O)ccc1O</smiles>

C)

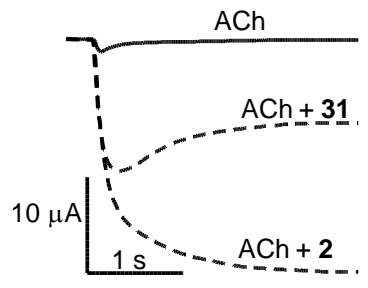

e)

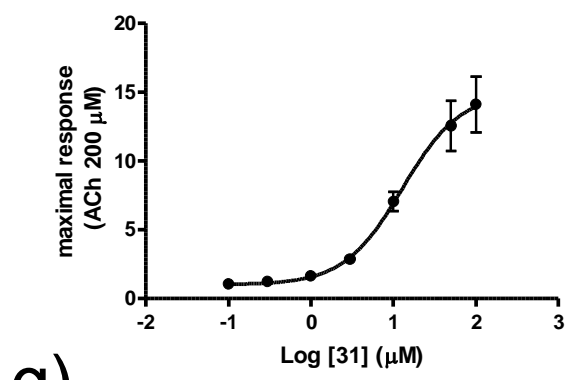

g)

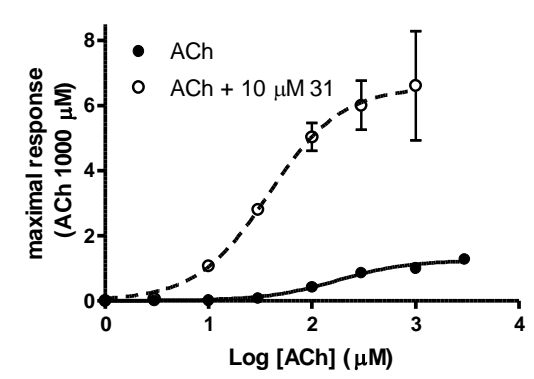

b)<smiles>O=C(CCc1ccc(O)cc1O)c1cc(O)ccc1O</smiles>

d)

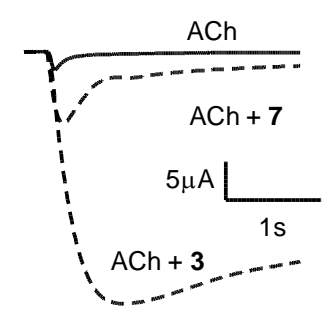

f)
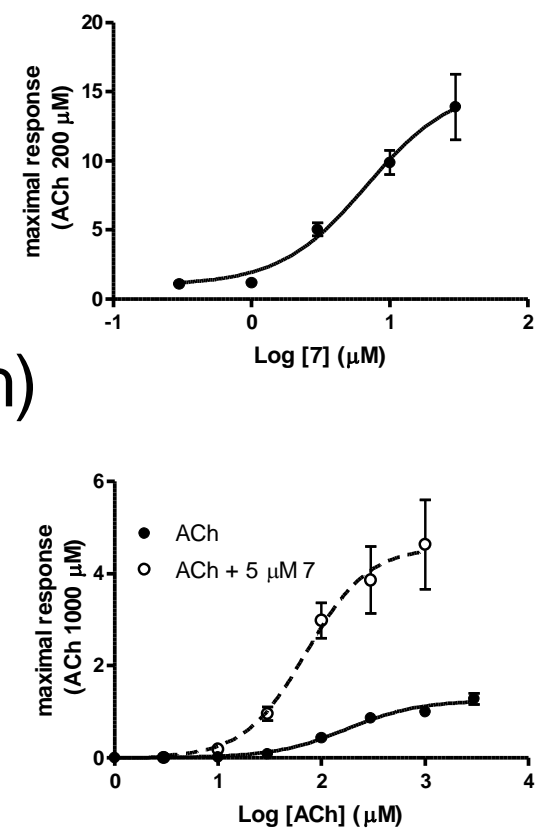

Figure 8. Comparison between compounds 31 (left panels) and $\mathbf{7}$ (right panels). a-b) Chemical structure of 1,3-diphenylpropan-1-ones $\mathbf{3 1}$ and 7. c-d) lonic currents recorded in representative oocytes expressing human $\alpha 7$ nAChRs. Currents were evoked by $600 \mathrm{~ms}$ applications of ACh $200 \mu \mathrm{M}$ in the absence (continuous line) and in the presence (dotted line) of $10 \mu \mathrm{M}$ of $\mathbf{3 1}$ or 7. For the sake of comparison, representative currents obtained with the chalcone analogues $\mathbf{2}$ and $\mathbf{3}$ were included. All currents were recorded at a holding potential of $-80 \mathrm{mV}$. e-f) Concentrationresponse relationships for the potentiating effect of $\mathbf{3 1}$ and $\mathbf{7}$ co-applied with ACh 200 $\mu \mathrm{M}$. Continuous lines represent the fit to the Hill equation. Maximal potentiating effects were estimated as 15 -fold for both compounds, with $\mathrm{EC}_{50}$ values of $12.9 \mu \mathrm{M}$ and $6.85 \mu \mathrm{M}$ for $\mathbf{3 1}$ and 7, respectively. g-h) Acetylcholine concentration-response relationships in the absence (closed circles) and in the presence (open circles) of the indicated concentration of each compound. These concentrations were chosen 
because they are close to their respective $\mathrm{EC}_{50}$ values. All data were normalized to the response obtained by $A C h 1 \mathrm{mM}$ in control conditions. Lines represent fits to Hill equations.

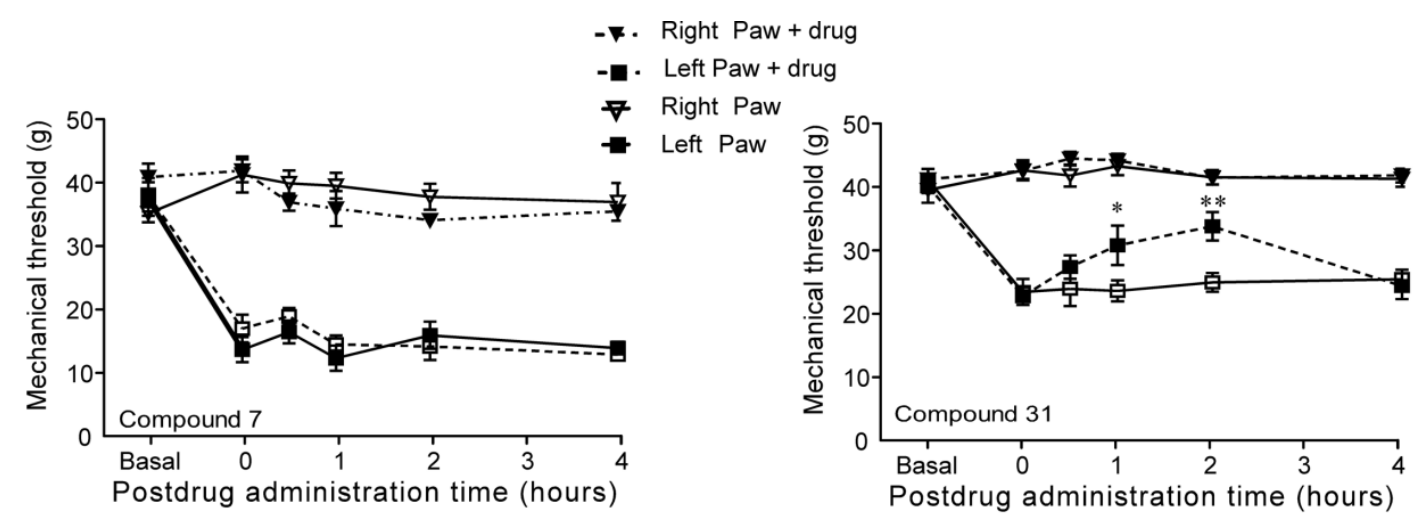

Figure 9. Effect of compound $\mathbf{7}$ and $\mathbf{3 1}$ in the CFA-induced paw inflammation model. Time course of mechanical hyperalgesia in rats after injection of CFA $0.5 \mathrm{mg} / \mathrm{mL}(50 \mu \mathrm{L})$ into the right hind paw with and without administration of compound ( $10 \mathrm{mg} / \mathrm{kg}$ i.v.). The diagram shows the paw withdrawal latencies in response to mechanical stimulation ( $n \geq 6$ rats/group). Data are given as mean \pm SEM $n=6$. 2-Way ANOVA with Bonferroni post hoc test. $* P<0.05 ; * * P<0.01, * * * P<0.001$. 
Table 1. Structures of methoxy parent compounds and their inhibition $\%$ values of $\alpha$ 7 nAChR currents ${ }^{a}$

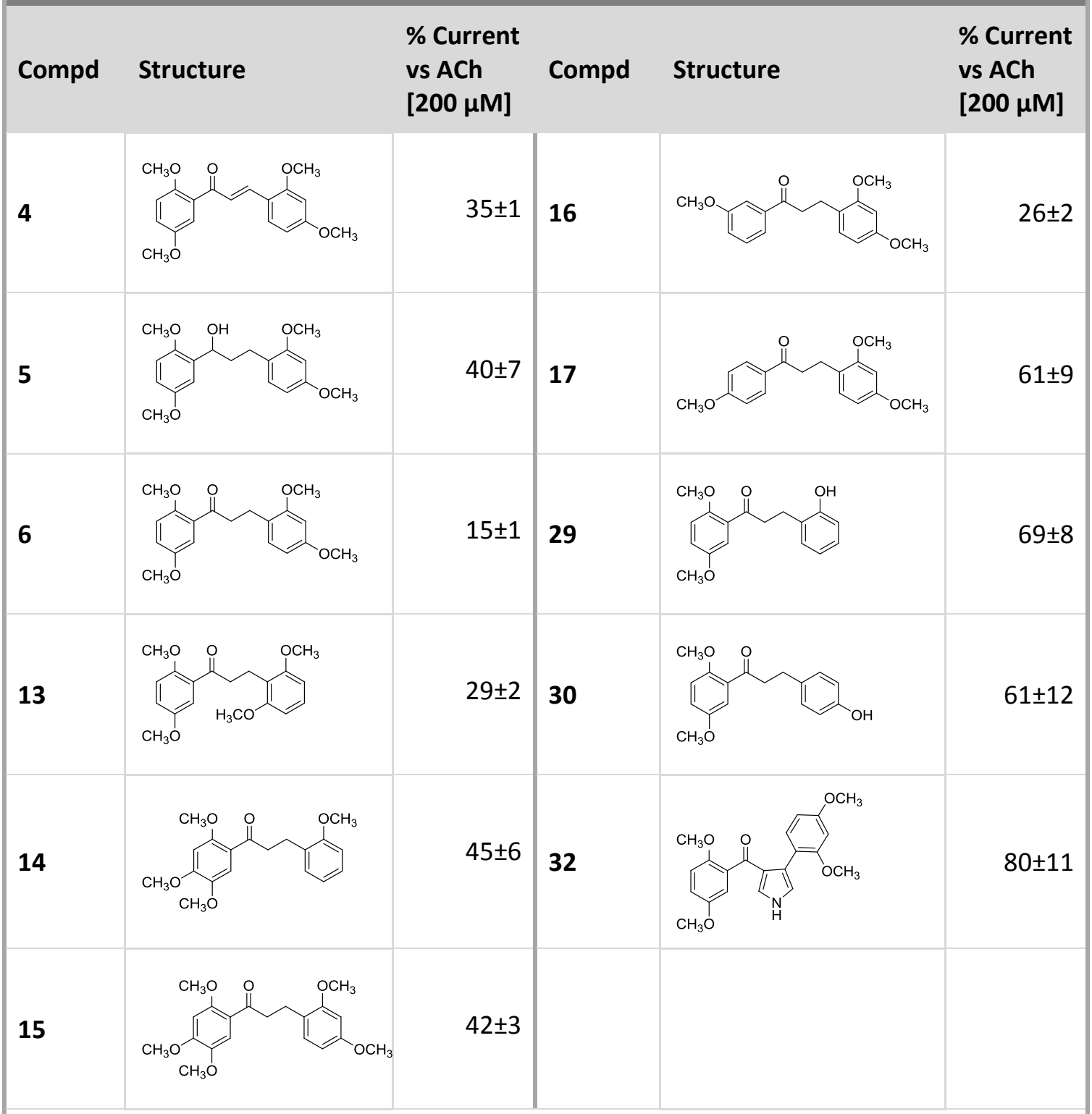

${ }^{a}$ The substituents 2 to 6 and 2 ' to 6 ' refer to the positions indicated at the structure shown above. Compounds were tested at $10 \mu \mathrm{M}$ co-applied with $200 \mu \mathrm{M}$ ACh Responses were recorded at $-80 \mathrm{mV}$ and normalized with respect to that shown by only ACh (200 $\mu \mathrm{M})$. 


Table 2. Structures of synthetized polyhydroxy synthesized compounds and their
potentiation \% values of $\alpha 7$ nAChR currents
Compd
$\begin{aligned} & \text { \% Current } \\ & \text { vs ACh } \\ & \text { [200 } \mu \mathrm{M}]\end{aligned}$ Compd

${ }^{a}$ The substituents 2 to 6 and $2^{\prime}$ to 6 ' refer to the positions indicated at the structure shown above. Compounds were tested at $10 \mu \mathrm{M}$ co-applied with $200 \mu \mathrm{M}$ ACh Responses were recorded at $-80 \mathrm{mV}$ and normalized with respect to that shown by only ACh $(200 \mu \mathrm{M})$. 


\begin{tabular}{|c|c|c|}
\hline Compound & $\operatorname{Imax}^{a}$ & $\mathrm{EC}_{50}(\mu \mathrm{M})^{a}$ \\
\hline 2 & $33.0 \pm 9.6^{b}$ & $25.0 \pm 2.8^{b}$ \\
\hline 31 & $15.0 \pm 1.9$ & $12.9 \pm 1.4$ \\
\hline 3 & $34.0 \pm 5.5$ & $3.3 \pm 1.6$ \\
\hline 7 & $15.5 \pm 1.2$ & $6.9 \pm 0.9$ \\
\hline \multicolumn{3}{|c|}{ 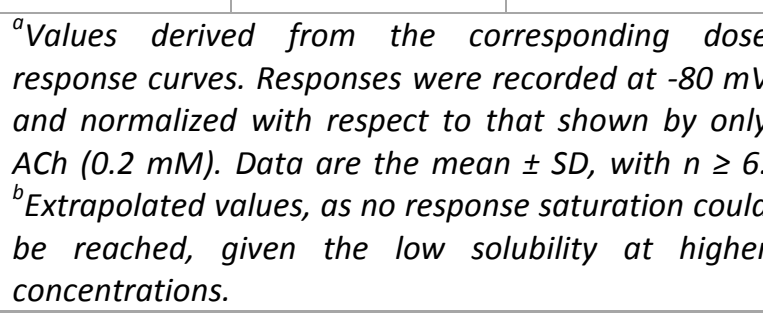 } \\
\hline
\end{tabular}

Table 4. Calculated Physicochemical Properties and Short ADME Profile of Compounds 3, 7 and 31 .

\begin{tabular}{|c|c|c|c|c|}
\hline \multicolumn{2}{|l|}{ Property } & Compd. 3 & Compd. 7 & Compd. 31 \\
\hline MW & & 272.25 & 274.27 & 258.27 \\
\hline CLogP & & $2.51^{a}$ & $2.66^{a}$ & $2.74^{\mathrm{a}}$ \\
\hline PSA & & $97.98^{a}$ & $97.9^{a}$ & $77.75^{a}$ \\
\hline \multirow{3}{*}{ Solubility ${ }^{b}(\mu M)$} & Intestinal fluid & 11.6 (LCP) & 184.2 & 188.4 \\
\hline & PBS (pH 7.4) & $6.4(\mathrm{LCP})$ & 176.4 & 159.9 \\
\hline & Gastric fluid & 38.8 (LCP) & 185.0 & 200.4 (ADJ) \\
\hline $\begin{array}{l}\text { \% Protein } \\
\text { bound }^{c}\end{array}$ & & 96 & 97 & 97 \\
\hline \multirow{2}{*}{ 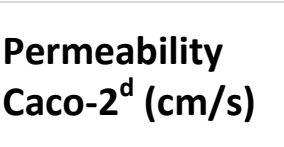 } & $A-B$ & $5.3 \times 10^{-6}$ & $3.1 \times 10^{-6}$ & $33.5 \times 10^{-6}$ \\
\hline & B-A & $19.9 \times 10^{-6}$ & $38.5 \times 10^{-6}$ & $12.0 \times 10^{-6}$ \\
\hline \multirow{2}{*}{ Metabolism ${ }^{\mathrm{e}}$} & Half-life (min) & 23 & 42 & 18 \\
\hline & $\mathrm{CL}_{\text {int }}(\mu \mathrm{L} / \mathrm{min} / \mathrm{mg})$ & 299.5 & 165.7 & 387.1 \\
\hline \multicolumn{5}{|c|}{$\begin{array}{l}{ }^{a} \text { Calculated using Molinspiration (http://www. molinspiration.com). } \\
b, c, d, e \text { Performed by CEREP. } L C P=\text { low chromatography purity due to compound instability (trans-ci } \\
\text { isomerism) at room temperature in PBS solution. ADJ = Solubility greater than } 200 \mu M \text {, adjusted to the } \\
\text { maximum assay concentration }(200 \mu M) \text {. }\end{array}$} \\
\hline
\end{tabular}




\begin{tabular}{|c|c|}
\hline Compd. & $\begin{array}{c}\mu \mathrm{M} \text { TE/ } / \text { mol of pure } \\
\text { compound }\end{array}$ \\
\hline 3 & $4.5 \pm 0.6$ \\
\hline 7 & $7.0 \pm 1.8$ \\
\hline 31 & $2.7 \pm 0.1$ \\
\hline
\end{tabular}




\section{References}

Papers of special note has been highlighted as:

- *of interest

- $\quad * *$ of considerable interest

1. Romanelli MN, Gratteri P, Guandalini L, Martini E, Bonaccini C, Gualtieri F. Central nicotinic receptors: structure, function, ligands, and therapeutic potential. ChemMedChem 2(6), 746-767 (2007).

2. D'souza MS, Markou A. Schizophrenia and tobacco smoking comorbidity: nAChR agonists in the treatment of schizophrenia-associated cognitive deficits. Neuropharmacology 62(3), 1564-1573 (2012).

3. Millar NS, Gotti C. Diversity of vertebrate nicotinic acetylcholine receptors. Neuropharmacology 56(1), 237-246 (2009).

4. Mazurov AA, Speake JD, Yohannes D. Discovery and development of a7 nicotinic acetylcholine receptor modulators. J. Med. Chem. 54(23), 7943-7961 (2011).

5. Toyohara J, Hashimoto K. $\alpha 7$ Nicotinic receptor agonists: potential therapeutic drugs for treatment of cognitive impairments in schizophrenia and Alzheimer's disease. Open Med. Chem. J. 437 (2010).

6. Beinat C, Banister S, Herrera M, Law V, Kassiou M. The therapeutic potential of $\alpha 7$ nicotinic acetylcholine receptor ( $\alpha 7 \mathrm{nAChR})$ agonists for the treatment of the cognitive deficits associated with schizophrenia. CNS Drugs 29(7), 529-542 (2015).

7. Williams DK, Wang J, Papke RL. Positive allosteric modulators as an approach to nicotinic acetylcholine receptor-targeted therapeutics: Advantages and limitations. Biochem. Pharmacol. 82(8), 915-930 (2011).

**Provides an overview of the scope and future of positive allosteric modulators of $\alpha 7 \mathrm{nACh}$ receptor.

8. Taly A, Corringer P-J, Guedin D, Lestage P, Changeux J-P. Nicotinic receptors: Allosteric transitions and therapeutic targets in the nervous system. Nat. Rev. Drug Discov. 8(9), 733-750 (2009).

* Provides a general overview about the nicotinic receptors allosteric transitions and their potential as therapeutics for nervous-system disorders.

9. Gill JK, Dhankher P, Sheppard TD, Sher E, Millar NS. A series of $\alpha 7$ nicotinic acetylcholine receptor allosteric modulators with close chemical similarity but diverse pharmacological properties. Mol. Pharmacol. 81(5), 710-718 (2012).

10. Hurst RS, Hajos M, Raggenbass $M$ et al. A novel positive allosteric modulator of the alpha 7 neuronal nicotinic acetylcholine receptor: In vitro and in vivo characterization. J. Neurosci. 25(17), 4396-4405 (2005).

11. $\mathrm{Ng} \mathrm{HJ}$, Whittemore ER, Tran MB et al. Nootropic alpha 7 nicotinic receptor allosteric modulator derived from GABA(A) receptor modulators. Proc. Natl. Acad. Sci. U. S. A. 104(19), 8059-8064 (2007).

12. Timmermann DB, Gronlien JH, Kohlhaas KL et al. An allosteric modulator of the alpha7 nicotinic acetylcholine receptor possessing cognition-enhancing properties in vivo. J. Pharmacol. Exp. Ther. 323(1), 294-307 (2007).

13. Kennett GA, Wood MD, Bright F et al. In vitro and in vivo profile of SB 206553, a potent 5-HT2C/5-HT2B receptor antagonist with anxiolytic-like properties. Brit. J. Pharmacol. 117(3), 427-434 (1996).

14. Faghih R, Gopalakrishnan SM, Gronlien JH et al. Discovery of 4-(5-(4-chlorophenyl)-2methyl-3-propionyl-1H-pyrrol-1-yl)benzenesulfona mide (A-867744) as a novel Positive allosteric modulator of the alpha 7 nicotinic acetylcholine receptor. J. Med. Chem. 52(10), 3377-3384 (2009). 
15. Malysz J, Grønlien JH, Anderson DJ et al. In vitro pharmacological characterization of a novel allosteric modulator of alpha 7 neuronal acetylcholine receptor, 4-(5-(4chlorophenyl)-2-methyl-3-propionyl-1H-pyrrol-1-yl)benzenesulfonamide (A-867744), exhibiting unique pharmacological profile. J. Pharmacol. Exp. Ther. 330(1), 257-267 (2009).

16. Dunlop J, Lock T, Jow B et al. Old and new pharmacology: Positive allosteric modulation of the alpha 7 nicotinic acetylcholine receptor by the 5hydroxytryptamine(2B/C) receptor antagonist SB-206553 (3,5-dihydro-5-methyl-N-3pyridinylbenzo 1,2-b:4,5-b ' di pyrrole-1(2H)-carboxamide). J. Pharmacol. Exp. Ther. 328(3), 766-776 (2009).

17. Chimienti F, Hogg RC, Plantard L et al. Identification of SLURP-1 as an epidermal neuromodulator explains the clinical phenotype of Mal de Meleda. Hum. Mol. Genet. 12(22), 3017-3024 (2003).

18. Clark RRB, Lamppu D, Libertine $L$ et al. Discovery of novel 2-((pyridin-3yloxy)methyl)piperazines as $\alpha 7$ nicotinic acetylcholine Receptor modulators for the treatment of inflammatory disorders. J. Med. Chem. 57(10), 3966-3983 (2014).

19. Hogenkamp DJ, Ford-Hutchinson TA, Li W-Y et al. Design, synthesis, and activity of a series of arylpyrid-3-ylmethanones as Type I positive allosteric modulators of $\alpha 7$ nicotinic acetylcholine receptors. J. Med. Chem. 56(21), 8352-8365 (2013).

20. Mazurov AA, Kombo DC, Hauser TA et al. Discovery of (2S,3R)-N-[2-(pyridin-3ylmethyl)-1-azabicyclo[2.2.2]oct-3-yl]benzo[b]furan-2-carboxamide (TC-5619), a selective $\alpha 7$ nicotinic acetylcholine receptor agonist, for the treatment of cognitive disorders. J. Med. Chem. 55(22), 9793-9809 (2012).

21. Thakur GA, Kulkarni AR, Deschamps JR, Papke RL. Expeditious synthesis, enantiomeric resolution, and enantiomer functional characterization of (4-(4-bromophenyl)3a,4,5,9b-tetrahydro-3H-cyclopenta[c]quinoline-8-sulfonamide (4BP-TQS): An allosteric agonist-positive allosteric modulator of $\alpha 7$ nicotinic acetylcholine receptors. J. Med. Chem. 56(21), 8943-8947 (2013).

22. Zanaletti R, Bettinetti L, Castaldo C et al. N-[5-(5-Fluoropyridin-3-yl)-1H-pyrazol-3-yl]-4piperidin-1-ylbutyramide (SEN78702, WYE-308775): A medicinal chemistry effort toward an $\alpha 7$ nicotinic acetylcholine receptor agonist preclinical candidate. J. Med. Chem. 55(22), 10277-10281 (2012).

23. Malysz J, Anderson DJ, Grønlien JH et al. In Vitro Pharmacological characterization of a novel selective alpha 7 neuronal nicotinic acetylcholine receptor agonist ABT-107. J. Pharm. Exp. Ther. 334863 (2010).

24. Gill-Thind JK, Dhankher P, D'oyley JM, Sheppard TD, Millar NS. Structurally similar allosteric modulators of $\alpha 7$ nicotinic acetylcholine receptors exhibit Five distinct pharmacological effects. J. Biol. Chem. 290(6), 3552-3562 (2015).

25. Balsera B, Mulet J, Fernández-Carvajal A et al. Chalcones as positive allosteric modulators of $\alpha 7$ nicotinic acetylcholine receptors: A new target for a privileged structure. Eur. J. Med. Chem. 86(0), 724-739 (2014).

* Describes the potent and selective activation of ACh-induced currents through $\alpha 7$ nAChR by related polyphenolic chalcones.

26. Stepan AF, Walker DP, Bauman J et al. Structural alert/reactive metabolite concept as applied in medicinal chemistry to mitigate the risk of idiosyncratic drug toxicity: A perspective based on the critical examination of trends in the top 200 drugs marketed in the united states. Chem. Res. Toxicol. 24(9), 1345-1410 (2011).

27. Mori A, Miyakawa Y, Ohashi E, Haga T, Maegawa T, Sajiki H. Pd/C-catalyzed chemoselective hydrogenation in the presence of diphenylsulfide. Organic letters 8(15), 3279-3281 (2006).

28. Mcomie JFW, Watts ML, West DE. Demethylation of aryl methyl ethers by boron tribromide. Tetrahedron 24(5), 2289-2292 (1968). 
29. Luche JL. Lanthanides in organic chemistry. 1 . Selective 1,2 reductions of conjugated ketones. J. Am. Chem. Soc. 100(7), 2226-2227 (1978).

30. Broad LM, Zwart R, Pearson KH et al. Identification and pharmacological profile of a new class of selective nicotinic acetylcholine receptor potentiators. J. Pharm. Exp. Ther. 318(3), 1108-1117 (2006).

31. Hormaza A, Arbelaez Perez OF. Síntesis de una nueva serie de pirroles vía cicloadición. Rev. Soc. Quim. Peru. 75 12-16 (2009).

32. Grønlien JH, Hakerud $\mathrm{M}$, Ween $\mathrm{H}$ et al. Distinct profiles of alpha $7 \mathrm{nAChR}$ positive allosteric modulation revealed by structurally diverse chemotypes. Mol. Pharmacol. 72(3), 715-724 (2007).

33. Freitas K, Carroll FI, Damaj MI. The antinociceptive effects of nicotinic receptors $\alpha 7-$ positive allosteric modulators in murine acute and tonic pain models. J. Pharm. Exp. Ther. 344(1), 264-275 (2013).

34. Freitas K, Ghosh S, Ivy Carroll F, Lichtman AH, Imad Damaj M. Effects of alpha 7 positive allosteric modulators in murine inflammatory and chronic neuropathic pain models. Neuropharmacology 65(0), 156-164 (2013).

35. Freitas K, Negus SS, Carroll FI, Damaj MI. In vivo pharmacological interactions between a type II positive allosteric modulator of $\alpha 7$ nicotinic ACh receptors and nicotinic agonists in a murine tonic pain model. Br. J. Pharmacol. 169(3), 567-579 (2013).

** Provides one of the first experimental evidences of the antinociceptive activity of $\alpha 7 \mathrm{nAChR}$ PAMs.

36. Hara K, Haranishi $\mathrm{Y}$, Kataoka $\mathrm{K}$ et al. Chlorogenic acid administered intrathecally alleviates mechanical and cold hyperalgesia in a rat neuropathic pain model. Eur. J. Pharmacol. 723(0), 459-464 (2014).

37. Sharma S, Kulkarni SK, Chopra K. Effect of resveratrol, a polyphenolic phytoalexin, on thermal hyperalgesia in a mouse model of diabetic neuropathic pain. Fundam. Clin. Pharmaco. 21(1), 89-94 (2007).

* Point towards the potential of resveratrol in attenuating neuropathic pain, thus oppening the use of other antioxidant polyphenols as analgesic agents.

38. Azevedo MI, Pereira AF, Nogueira RB et al. The antioxidant effects of the flavonoids rutin and quercetin inhibit oxaliplatin-induced chronic painful peripheral neuropathy. Mol. Pain 9 53-953 (2013).

39. Aboul-Enein HY, Berczynski P, Kruk I. Phenolic compounds: the role of redox regulation in neurodegenerative disease and cancer. Mini-Rev. Med. Chem. 13(3), 385-398 (2013).

40. Bubols GB, Vianna DDR, Medina-Remon A et al. The Antioxidant Activity of Coumarins and Flavonoids. Mini-Rev. Med. Chem. 13(3), 318-334 (2013).

41. Quiñones $M$, Miguel $M$, Aleixandre $A$. Beneficial effects of polyphenols on cardiovascular disease. Pharmacol. Res. 68(1), 125-131 (2013).

42. Katz DL, Doughty K, Ali A. Cocoa and chocolate in human health and disease. Antioxid. Redox Signal. 15(10), 2779-2811 (2011).

43. Rezk BM, Haenen GRMM, Van Der Vijgh WJF, Bast A. The antioxidant activity of phloretin: the disclosure of a new antioxidant pharmacophore in flavonoids. Biochem. Biophys. Res. Commun. 295(1), 9-13 (2002).

44. Dávalos A, Gómez-Cordovés C, Bartolomé B. Extending applicability of the oxygen radical absorbance capacity (ORAC-fluorescein) assay. J. Agric. Food Chem. 52(1), 4854 (2004).

45. Sueishi $Y$, Ishikawa M, Yoshioka D et al. Oxygen radical absorbance capacity (ORAC) of cyclodextrin-solubilized flavonoids, resveratrol and astaxanthin as measured with the ORAC-EPR method. J. Clin. Biochem. Nutr. 50(2), 127-132 (2012).

46. Tsvetkova D, Obreshkova D, Zheleva - Dimitrova D, Saso L. Antioxidant activity of galantamine and some of its derivatives. Curr. Med. Chem. 20(36), 4595-4608 (2013). 
47. Zhang X, Wu M, Lu F, Luo N, He Z-P, Yang H. Involvement of alpha 7 nAChR Signaling Cascade in Epigallocatechin Gallate Suppression of beta-Amyloid-Induced Apoptotic Cortical Neuronal Insults. Molecular Neurobiology 49(1), 66-77 (2014).

48. García-Martínez C, Fernández-Carvajal A, Valenzuela B et al. Design and characterization of a noncompetitive antagonist of the transient receptor potential vanilloid subunit 1 channel with In vivo analgesic and anti-inflammatory activity. J. Pain 7(10), 735-746 (2006).

49. Ou B, Hampsch-Woodill M, Prior RL. Development and validation of an improved oxygen radical absorbance capacity assay using fluorescein as the fluorescent probe. $J$. Agric. Food Chem. 49(10), 4619-4626 (2001).

50. Tracey KJ. The inflammatory reflex. Nature 420(6917), 853-859 (2002).

51. Ulloa L. The vagus nerve and the nicotinic anti-inflammatory pathway. Nat Rev Drug Discov 4(8), 673-684 (2005).

52. Van Westerloo DJ, Giebelen IA, Florquin $S$ et al. The vagus nerve and nicotinic receptors modulate experimental pancreatitis severity in mice. Gastroenterology 130(6), 1822-1830 (2006).

53. Ghia JE, Blennerhassett P, Kumar-Ondiveeran H, Verdu EF, Collins SM. The vagus nerve: a tonic inhibitory influence associated with inflammatory bowel disease in a murine model. Gastroenterology 131(4), 1122-1130 (2006).

54. The FO, Boeckxstaens GE, Snoek SA et al. Activation of the cholinergic antiinflammatory pathway ameliorates postoperative ileus in mice. Gastroenterology 133(4), 1219-1228 (2007). 